\title{
Combined ESR and EISCAT observations of the dayside polar cap and auroral oval during the May 15, 1997 storm
}

\author{
H. Liu ${ }^{1,2}$, K. Schlegel ${ }^{1}$, S.-Y. Ma ${ }^{2,3}$ \\ ${ }^{1}$ Max-Planck-Institut für Aeronomie, Max-Planck-Str. 2, D-37191 Katlenburg-Lindau, Germany \\ e-mail: liu@linmpi.mpg.de \\ ${ }_{2}^{2}$ Space physics department, Wuhan University, Wuhan 430072, China \\ ${ }^{3}$ Wuhan Ionospheric Observatory, Wuhan Institute of Physics and Mathematics, Chinese Academy of Science, Wuhan 430071, China
}

Received: 21 December 1999 / Revised: 3 March 2000 / Accepted: 17 March 2000

\begin{abstract}
The high-latitude ionospheric response to a major magnetic storm on May 15, 1997 is studied and different responses in the polar cap and the auroral oval are highlighted. Depletion of the $F_{2}$ region electron density occurred in both the polar cap and the auroral zone, but due to different physical processes. The increased recombination rate of $\mathrm{O}^{+}$ions caused by a strong electric field played a crucial role in the auroral zone. The transport effect, however, especially the strong upward ion flow was also of great importance in the dayside polar cap. During the main phase and the beginning of the recovery phase soft particle precipitation in the polar cap showed a clear relation to the dynamic pressure of the solar wind, with a maximum cross-correlation coefficient of 0.63 at a time lag of $5 \mathrm{~min}$.
\end{abstract}

Key words: Ionosphere (auroral ionosphere; polar ionosphere) - Magnetospheric physics (storms and substorms)

\section{Introduction}

The ionospheric storm is a chain of events in general caused by the energy transferred from the solar wind to the magnetosphere during periods of southward interplanetary magnetic field (IMF). According to variations of the maximum electron density in the $F_{2}$ region $\left(\mathrm{N}_{m} \mathrm{~F}_{2}\right)$, the ionosphere may show a positive or a negative storm phase, with enhancement or depletion of $\mathrm{N}_{m} \mathrm{~F}_{2}$. The negative storm phase is usually caused by changes in the thermospheric composition and the positive one by elevated $F$ region heights driven by disturbed thermospheric winds (Szuszczewicz et al., 1998). Other mechanisms, e.g. effects of heating and vibrationally excited constituents on reaction rates, or

Correspondence to: Huixin Liu the escape of plasma upward along the magnetic field line were also discussed (Richards and Torr, 1986; Pavlov, 1998). The ionospheric response varies strongly with latitude. In the auroral zone the $\mathrm{F}_{2}$ region usually exhibits a negative storm phase, but the $\mathrm{E}$ region a positive one due to strong particle precipitation. In contrast to extensive studies of storm effects in the auroral region, ionospheric responses in the polar cap have been studied far less intensively, especially at low altitudes $(<600 \mathrm{~km})$ due to various difficulties in observation. Combined observations of the auroral and the polar cap ionosphere will provide a better understanding of the storm-time high-latitude ionosphere and physical processes of geomagnetic storms.

The EISCAT Svalbard (ESR) and the mainland Troms $\varnothing$ radar are located at $78^{\circ} \mathrm{N}$ geographic $\left(74^{\circ}\right.$ geomagnetic) and $69.7^{\circ} \mathrm{N}$ geographic $\left(66^{\circ}\right.$ geomagnetic) latitudes, respectively. Under disturbed conditions the auroral oval expands equatorward and the polar cap boundary moves to lower latitude as well (Holzworth and Meng, 1984). The ESR was in the dayside polar cap (on open field lines) during the main phase and the beginning of the recovery phase of the May 15, 1997 storm according to results calculated by using the T96 magnetic field model. The EISCAT Tromsø radar was in the dayside auroral oval (on closed field lines) during the same period, which was proven by the UV images taken from the ultraviolet imager (UVI) on board the POLAR satellite (Torr et al., 1995). This situation provides us with a valuable opportunity to observe storm effects in both the polar cap and the auroral oval simultaneously.

\section{Observations}

\subsection{Solar-geophysical conditions}

Figure 1 shows 1-min integrated solar wind and IMF data (in GSM coordinates) from the WIND spacecraft, together with the related geomagnetic indices for May 15, 1997. WIND observed the passage of an 
May 15, 1997

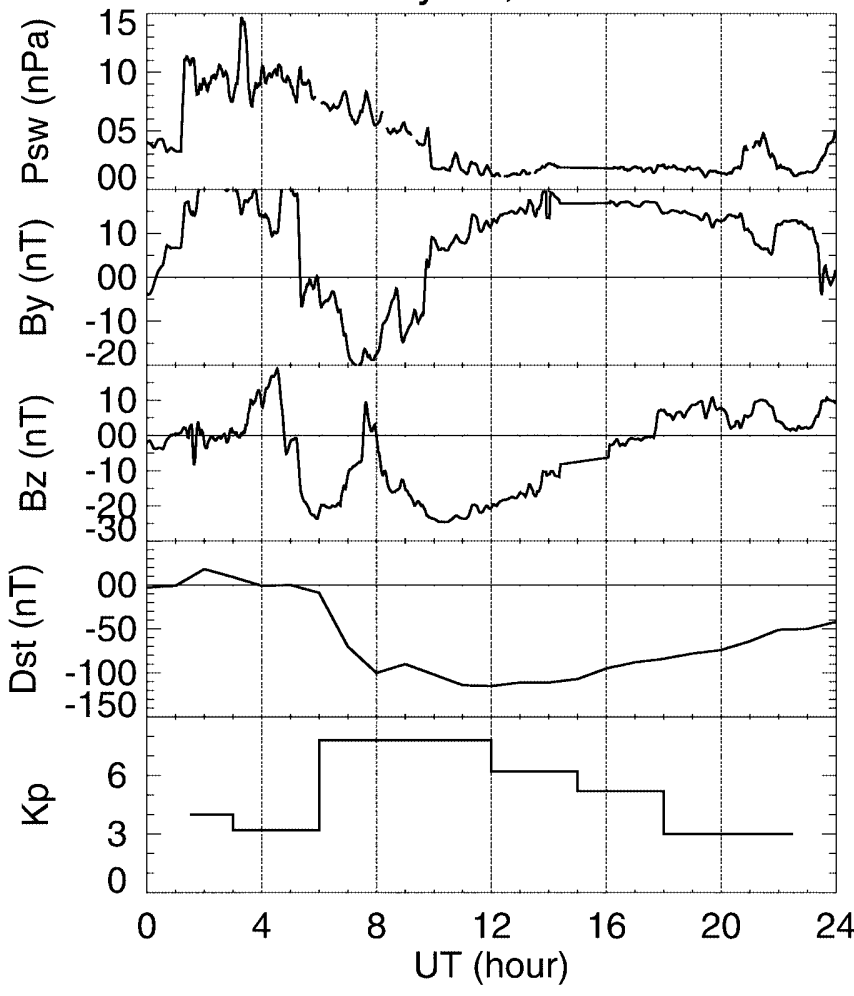

Fig. 1. The solar wind dynamic pressure, the IMF $B_{y}$ and $B_{z}$ component, the $\mathrm{D}_{s t}$ and $K p$ index on May 15, 1997

interplanetary shock at 0116 UT, followed by several hours of high solar wind dynamic pressure. The arrival of the magnetic cloud at the WIND location was marked by a sharp southward turning of the IMF $B_{z}$ at 0446 UT (Cane et al., 1998). The IMF $B_{z}$ showed two minima, the first minimum of $-24.3 \mathrm{nT}$ at $0556 \mathrm{UT}$ and the second one of $-24.7 \mathrm{nT}$ at 1023 UT followed by a long period of gradual recovery to a northward direction. WIND was located at $X_{s e}=1.21 \times 10^{6} \mathrm{~km}$ at $1200 \mathrm{UT}$ and the $X$ component of the solar wind velocity $V_{x}$ was $-440 \mathrm{~km} \mathrm{~s}^{-1}$, giving a travelling time of $\sim 43 \mathrm{~min}$ from the position of the WIND spacecraft to the subsolar magnetopause.

The $\mathrm{D}_{s t}$ index rose slightly at $0159 \mathrm{UT}$, indicating the storm sudden commencement (SSC) caused by the interplanetary shock at 0116 UT (Cane et al., 1998). After being nearly constant for four hours, it decreased rapidly and reached a minimum of $-120 \mathrm{nT}$ at $1200 \mathrm{UT}$. Afterwards it recovered gradually to the normal level. The maximum $K p$ value was $7^{+}$.

\subsection{Storm effects in the auroral zone}

Figure 2 shows the key ionospheric parameters measured by the EISCAT mainland radar in the auroral zone. The electron density $N_{e}$ and the field-parallel ion temperature $T_{i}$ are averaged over a height range 250$350 \mathrm{~km}$. The electric field was derived from the tri-static ion drift measurement at a height of $278.5 \mathrm{~km}$. The Joule heating rate is height-integrated over the range

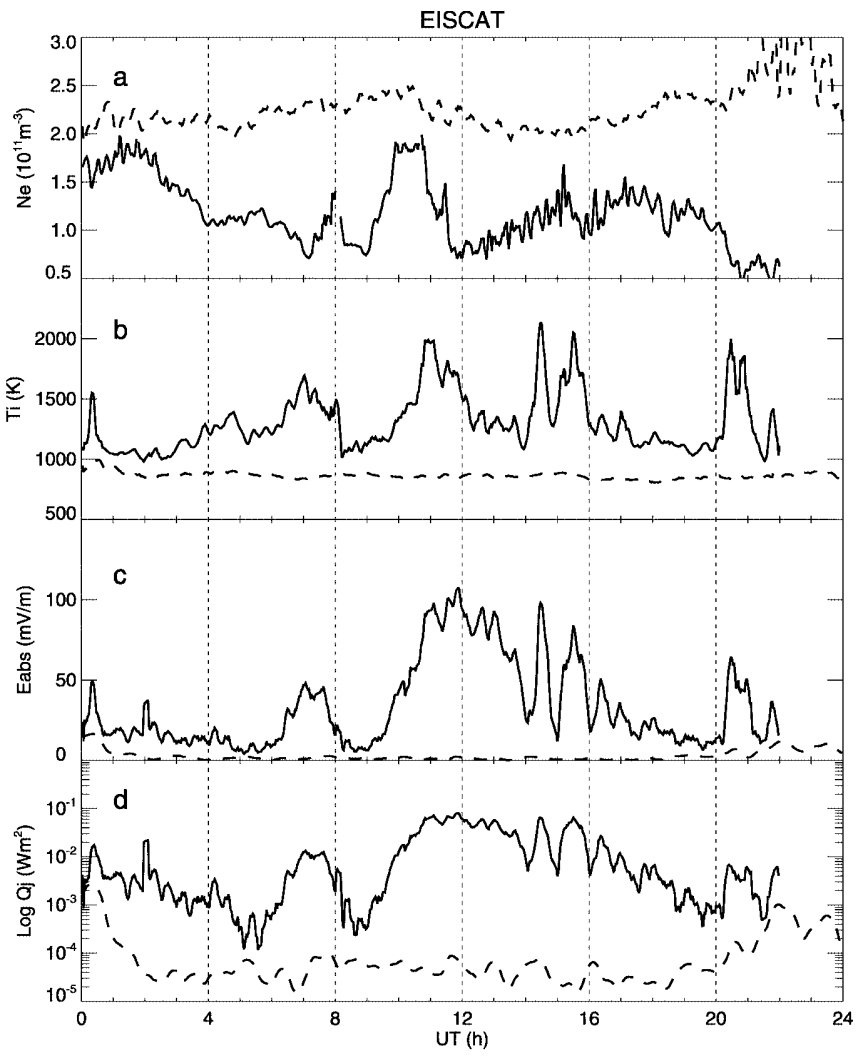

Fig. 2. Time variation of the electron density $\left(N_{e}\right)$, the ion temperature $\left(T_{i}\right)$, the electric field $\left(E_{a b s}\right)$ and the Joule heating $\left(Q_{j}\right)$ measured by EISCAT. Dashed curves: a quiet reference day (June 26, 1997). Solid curves: storm time on May 15, 1997

90-240 km. Dashed curves represent values on June 26, 1997, a magnetically quiet day with $K p_{\max }=2$, shown here as a reference.

The $\mathrm{F}_{2}$ region exhibited a negative storm effect through the whole day, with average $N_{e}$ depleted from the quiet reference level of $2.3 \times 10^{11}$ to $0.7 \times 10^{11} \mathrm{~m}^{-3}$ in the storm main phase. This large depletion was caused by strong electric fields (see Fig. 2c), which peaked to $120 \mathrm{mV} \mathrm{m}^{-1}$ during the storm main phase, nearly ten times the quiet-time value. As a result, this large electric field caused strong Joule heating in the ionosphere (Fig. 2d), thereby heating the ions from about 900 to nearly $2000 \mathrm{~K}$. Simultaneously, the heating in the E region resulted in an increase of the neutral temperature and an upwelling of the neutral gas, providing enriched concentrations of molecules (e.g., $\mathrm{N}_{2}$ and $\mathrm{O}_{2}$ ) in the $\mathrm{F}$ region. Both processes contribute to the $F_{2}$-region depletion mainly by increasing the recombination rate of $\mathrm{O}^{+}$ions. The detailed physical mechanism of strong negative storm effects in the $\mathrm{F}_{2}$ region has been studied by Mikhailov and Schlegel (1998) and references therein. Enhancements of $N_{e}$ around $0800 \mathrm{UT}$ and between 0900-1100 UT are caused by particle precipitation.

It should be noted that the peak ion temperature may be underestimated in our data because of a possible ion temperature anisotropy and a more molecular ion composition than accounted for by the standard EISCAT data analysis during periods of large electric field 
(Mikhailov and Schlegel, 1998). Since we are not aiming at a quantitative study but rather want to make a qualitative comparison, we did not attempt a correction of $T_{i}$.

\subsection{Storm effects in the polar cap}

The electron density and the field-parallel ion temperature measured by the ESR radar are shown in Fig. 3. They are height-averaged between $250-350 \mathrm{~km}$. The dashed curves correspond to a quiet reference day with $K p_{\max }=1$. The $\mathrm{F}_{2}$ region again exhibited a negative phase, with the average electron density strongly depleted from a reference level of $1.5 \times 10^{11}$ to $0.6 \times 10^{11} \mathrm{~m}^{-3}$, similar to the depletion in the auroral zone. The ion temperature $T_{i}$, however, was only weakly enhanced from 1000 to $1200 \mathrm{~K}$, much less than that in the auroral zone. Assuming the enhancement of $T_{i}$ is an indicator of the frictional heating and the electric field (Davies et al., 1999; Rees and Walker, 1968), the low $T_{i}$ in the polar cap demonstrates that the electric field was not strong during that period.

To see the difference in the auroral zone and the polar cap through the whole ionosphere, a snapshot of the height profile of $N_{e}$ and $T_{i}$ at 1106 UT overhead the ESR and EISCAT Tromsø radar is shown in Fig. 4. The electron density in the $\mathrm{F}$ region between $200-300 \mathrm{~km}$ was obviously depleted at both sites, to more or less the same extent. But $T_{i}$ behaved quite differently, with enhancement from about 900 to $2000 \mathrm{~K}$ in the auroral zone, from 1000 to only $1200 \mathrm{~K}$ in the polar cap. This large difference again indicates that the electric field in the polar cap was much lower than that in the auroral zone. As mentioned in Sect. 2.2, the depletion of the $F_{2}$ region in the auroral zone was mainly due to the increased recombination rate caused by large electric field. The remaining question is why the depletion in the polar cap was so strong in spite of the weak electric field.

A possible answer lies in the horizontal and vertical transport. First, the convection velocity is antisunward

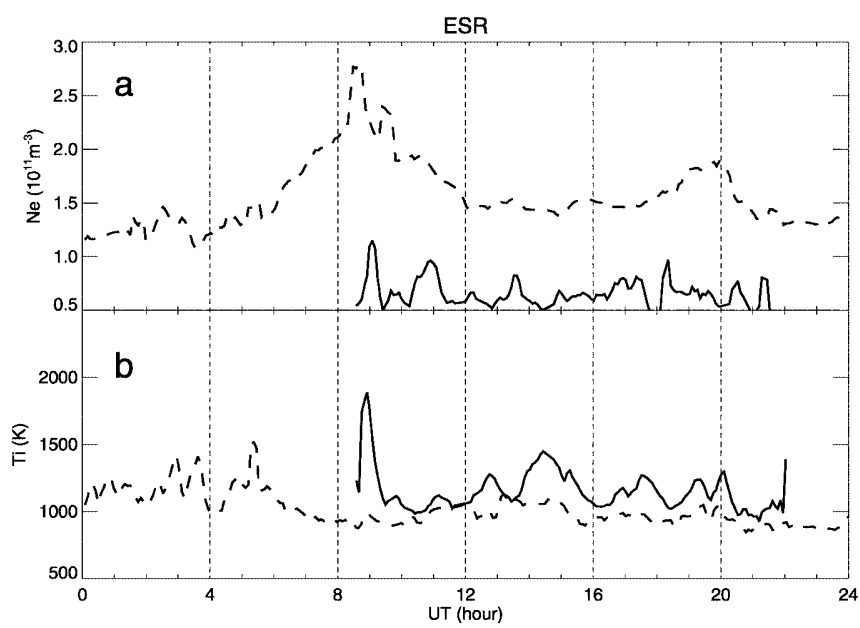

Fig. 3. Time variation of $N_{e}$ and $T_{i}$ measured by ESR (averaged between 250-350 km). Dashed curves: a quiet reference day (June 5, 1997). Solid curves: storm time on May 15, 1997
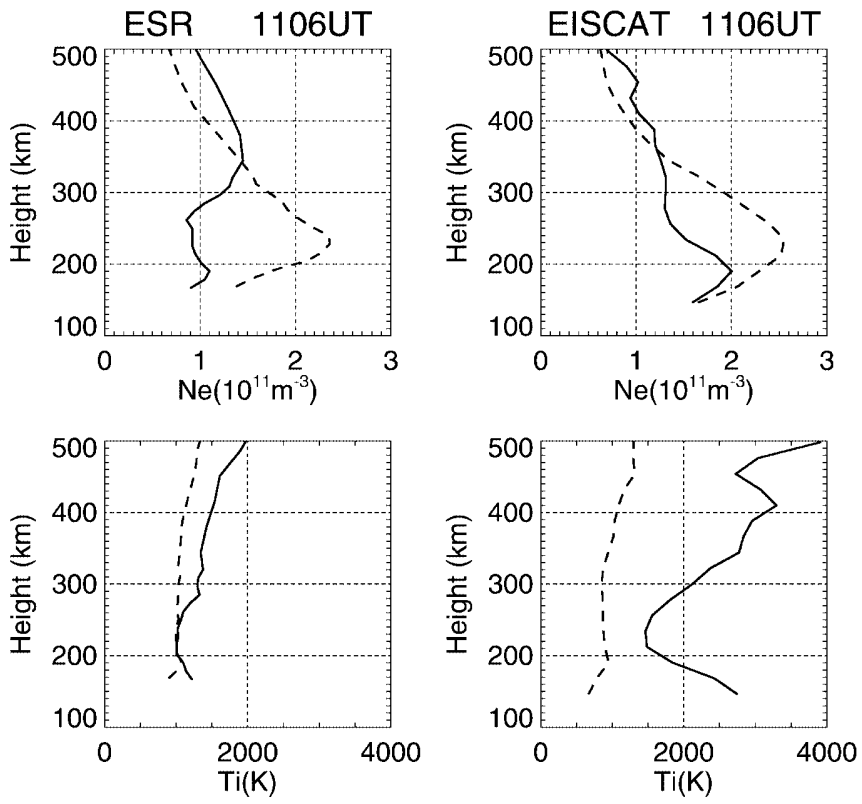

Fig. 4. Height profiles of $N_{e}$ and $T_{i}$ measured by ESR (left) and EISCAT (right) under both quiet (dashed) and disturbed (solid) conditions

at the dayside polar cap boundary, which can bring strongly depleted plasma from the auroral zone thus contribute to the negative storm phase in the polar cap. The convection velocity in the auroral zone was up to $2.5 \mathrm{~km} \mathrm{~s}^{-1}$ during storm time, which reinforced this effect. Another very important factor is the vertical transport, which is shown in Fig. 5. The field-aligned ion velocity was upward along the magnetic field throughout the upper ionosphere, which can cause a lifting of the $F_{2}$ layer. In addition, a large upward velocity gradient existed between $200-300 \mathrm{~km}$ altitude, which also resulted in direct loss of the ions $\left(\mathrm{O}^{+}\right)$to higher region. These processes together with the moderate

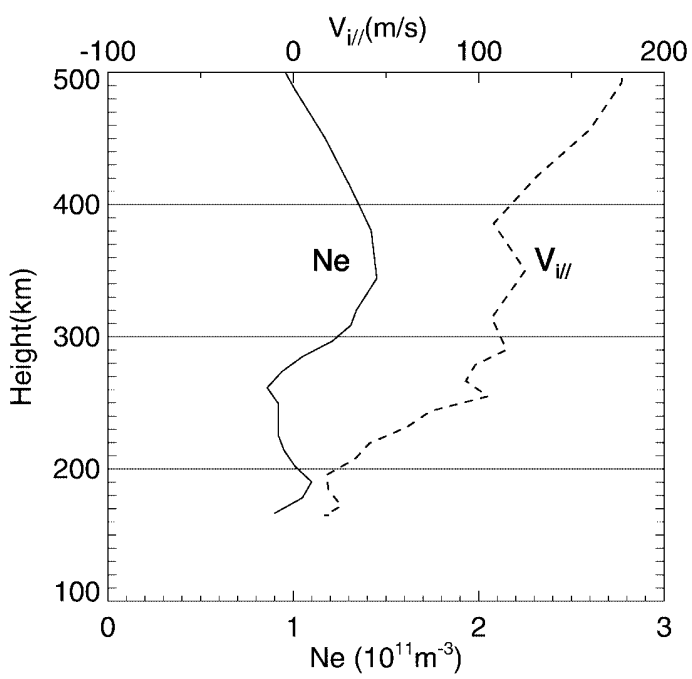

Fig. 5. Height profiles of $N_{e}$ (solid curve, bottom scale) and the fieldaligned ion velocity $V_{i \|}$ (dashed, top scale) measured by ESR at 1106 UT on May 15, 1997 

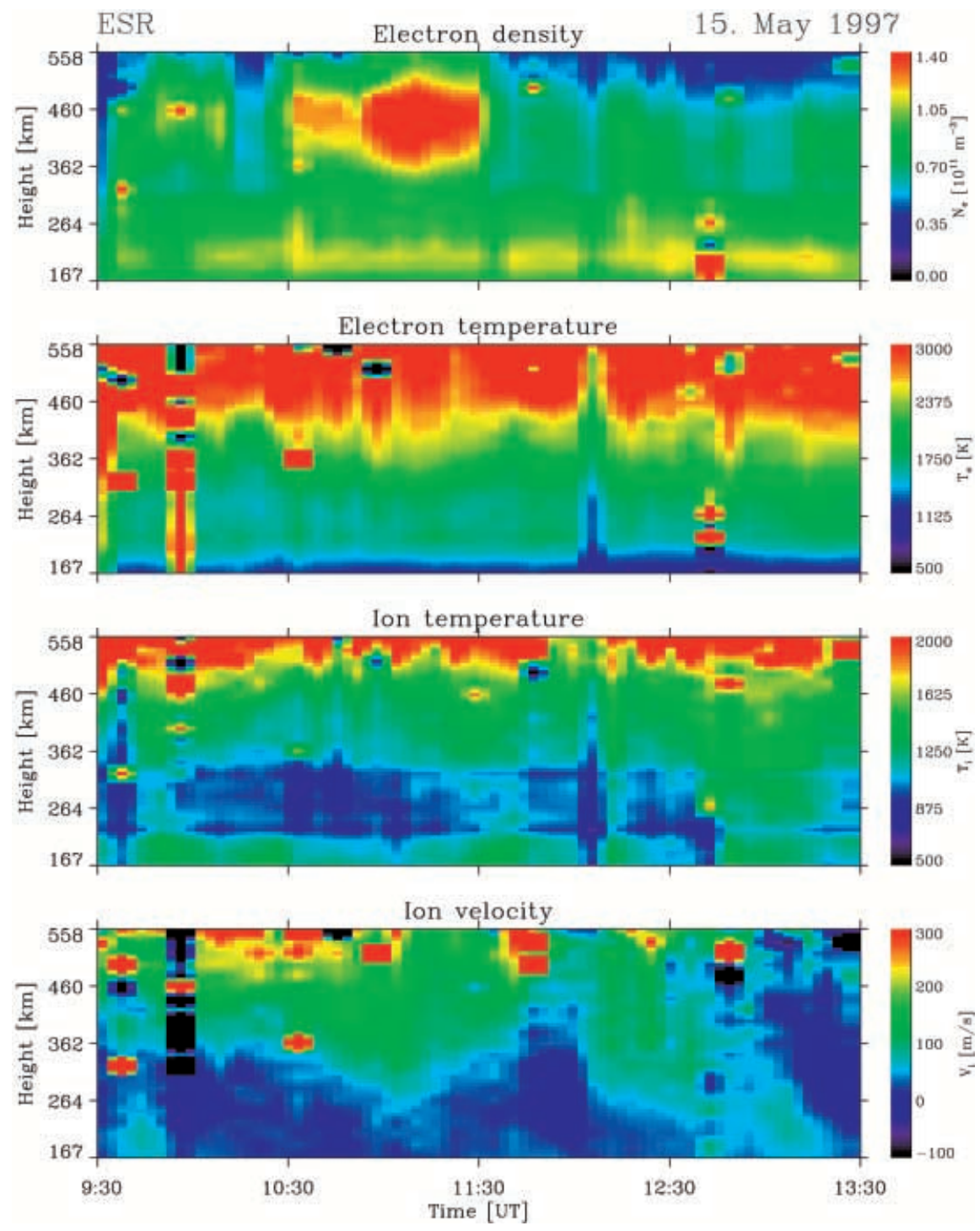

Fig. 6. Key parameters measured by ESR on May 15, 1997. LT $=\mathrm{UT}+1$
Joule heating contributed to the $\mathrm{F}_{2}$ region depletion in the dayside polar cap.

The increase of the electron density at heights between $360-510 \mathrm{~km}$ is also worth noticing. It developed into a layer during 1030-1130 UT, which can be seen very clearly in Fig. 6. Its temporal variation showed a broadening, but its mean height remained nearly constant at around $380 \mathrm{~km}$. The aforementioned uplifting effect from the upward ion velocity can contribute to this $N_{e}$ enhancement, but it is probably not the only cause. By examining the UV images taken by the POLAR satellite we found that precipitation occurred during the same period. According to the simulation results of Millward et al. (1999) precipitating electrons with energy of $100 \mathrm{eV}$ can cause ionization with a peak height around $370 \mathrm{~km}$ and thus contribute to the $N_{e}$ enhancement around this height. This precipitation also tends to maintain the layer at this height, which counteracts the uplift from the upward ion velocity. The broadening and the quasi-stationary mean height of the layer may therefore result from such a complicated competition.

\section{Discussion}

\subsection{Upward ion flow}

We concluded in the previous section that the upward ion velocity made a very important contribution to the $\mathrm{F}_{2}$-region depletion in the dayside polar cap during the May 15, 1997 storm. Although only a snapshot of the height profile of $V_{i \|}$ has been shown in Fig. 5, this strong upward ion flow persisted for a long time rather than being a transient event. Figure 6 shows the height and temporal variation of the key parameters measured by ESR. The bottom panel shows that $V_{i \|}$ was upward for more than $3 \mathrm{~h}$ from 0930 to $1230 \mathrm{UT}$, at all altitudes above $200 \mathrm{~km}$. This is different from Winser et al. (1988), who observed large upward ion flow near the polar cap boundary only in the midnight-dawn sector. The speed of this ion upflow even reached $300 \mathrm{~m} \mathrm{~s}^{-1}$ at $550 \mathrm{~km}$ at some time. As it increased with height it is interesting to speculate that this ion upflow may be associated with an outflow at the topside ionosphere and higher altitudes (Lookwood, 1982; 
Shelly et al., 1982; Yau et al., 1985; Waite et al., 1985). If this is indeed the case, the observation would be in agreement with Waite et al. (1985) stating that the outflow of $\mathrm{O}^{+}$in the polar cap exhibits a wide spatial and temporal extent under active magnetic conditions, and that it is strongest in the 1000-1600 MLT sector. Satellite data are needed for a final proof to identify any ion outflow above $1000 \mathrm{~km}$ during the corresponding period. Unfortunately, no appropriate data are available so far.

During the period of large field-aligned ion velocity, soft-particle precipitation and corresponding enhancements in $T_{e}$ above $350 \mathrm{~km}$ were also observed, but there was no strong enhancement in $T_{i}$. This disagrees with the idea that strong Joule heating is necessary for upflows (Winser et al., 1986, 1988; Williams and Jain, 1986). However, it is in accordance with observations by Ogawa et al. (2000). By using simultaneous ESR and EISCAT VHF observations they found that ion upflows are associated with a significant anisotropy of the ion temperature, isotropic increases of the electron temperature and soft particle precipitation. The result of Liu et al. (1995) is also supported by our observation. They demonstrated, by using simulations, that soft-electron precipitation can rapidly enhance the Fregion ionization and the electron temperature, leading to a strong upward plasma expansion, while the more widely recognized Joule heating is indicated to have "significant but somewhat smaller effects on the upflows".

\subsection{Effects of the solar wind dynamic pressure on the F-region electron density in the polar cap}

Although the F-region electron density in the polar cap was depleted with respect to the quiet level it showed a temporal variation with several maxima (Fig. 7). These large enhancements were probably caused by particle precipitation, which can be inferred from the UV images taken by the POLAR UVI imager. The top panel of Fig. 6 reveals that the altitudes where $N_{e}$ enhancements occurred are between 360 and $510 \mathrm{~km}$, higher than that in the auroral oval $(160-220 \mathrm{~km})$. Assuming these enhancements were mainly caused by precipitation, the energy of depositing electrons in these two regions should be around $100 \mathrm{eV}$ and $1000 \mathrm{eV}$, respectively (Millward et al., 1999). This confirms the conclusion of Meng and Makita (1986) that precipitating particles are of lower energy in the polar cap than in the auroral oval.

The dynamic pressure of the solar wind exhibited a similar time variation as the electron density. In particular, a peak-to-peak correspondence is observed at around 0910 UT, 0945 UT and 1035 UT (Fig. 7). To investigate their relation quantitatively cross-correlation analysis was carried out during the period from 0840 to 1230 UT. The result is shown at the bottom panel of Fig. 7. A cross-correlation coefficient of 0.63 with a time lag of 5 min demonstrates the close relationship between soft-particle precipitation in the polar cap and the dynamic pressure of the solar wind.
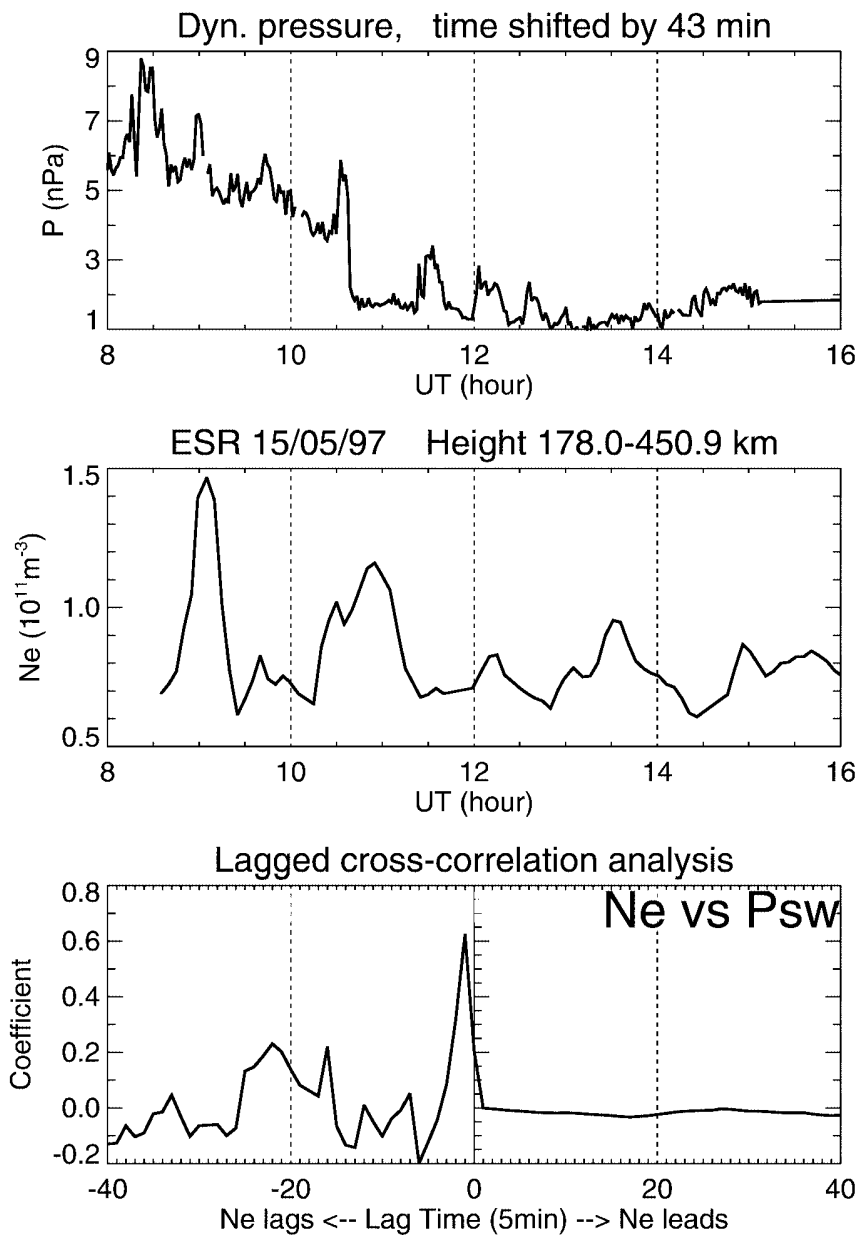

Fig. 7. The solar wind dynamic pressure, the height-averaged electron density and their cross-correlation coefficients

\section{Summary}

A negative storm phase was observed in both the polar cap and the auroral zone during the May 15, 1997 storm. In the auroral zone, the increased recombination rate caused by strong Joule heating during periods of large electric field was the main reason. In the polar cap, the strong upward ion flow was an important factor as well. Advection of low-density plasma from the auroral zone to the polar cap may also contribute to the depletion.

The strong ion upflow showed an extended spatial and temporal extent along the dayside polar cap. According to the simulation result of Liu et al. (1995), it was probably driven by soft-particle precipitation rather than strong Joule heating. However, as this ion upflow was observed at lower heights than in former observations, more work is necessary to clarify its acceleration mechanism.

During this storm event, particle precipitation occurred in both the polar cap and the auroral zone with the former characterized by relatively low energy electrons, which confirms the results of Meng and Makita (1986). 
The dynamic pressure of the solar wind showed a strong influence on the storm-time electron density in the polar cap, possibly by controlling soft-particle precipitation.

Acknowledgements. We are grateful to the director and staff of EISCAT for operating the facility and supplying the data. EISCAT is an international association supported by Finland (SA), France (CNRS), Germany (MPG), Japan (NIPR), Norway (NFR), Sweden (NFR), and the United Kingdom (PPARC). Thanks also to the staff of WDC-C2, Kyoto, and CDA web for providing geomagnetic indices and public POLAR, WIND satellite data. This study is supported by grants from DAAD and Grant 49674241 from the National Natural Science Foundation of China.

Topical Editor M. Lester thanks S. Buchert and A. Yau for their help in evaluating this paper.

\section{References}

Cane, H. V., I. G. Richardson, and O. C. St Cyr, The interplanetary events of January-May, 1997 as inferred from energetic particle data, and their relationship with solar events, Geophys. Res. Lett., 25, 2517-2520, 1998.

Davies, J. A., M. Lester, and I. W. McCrea, Solar and seasonal dependence of ion frictional heating, Ann. Geophysicae, 17, 682$691,1999$.

Holzworth, R. H., and C.-I. Meng, Auroral boundary variations and the interplanetary magnetic field, Planet. Space Sci., 32, 25-29, 1984.

Liu, C., J. L. Horwitz, and P. G. Richards, Effects of frictional heating and soft-electron precipitation on high-latitude F-region upflows, Geophys. Res. Lett., 22, 2713-2716, 1995.

Lookwood, M., Thermal ion flows in the topside auroral ionosphere and the effects of low-altitude transverse acceleration, Planet. Space Sci., 30, 595-609, 1982.

Meng, C.-I., and K. Makita, Dynamic variations of the polar cap, in Solar wind-magnetospheric coupling, Eds, Y. Kamide, J. Slavin, and D. Reidel Publishing Company, Dordrecht, Holland. 605-631, 1986.

Millward, G. H., R. J. Moffett, and H. F. Balmforth, Modeling the ionospheic effects of ion and electron precipitation in the cusp, J. Geophys. Res., 104, 24 603-24 612, 1999.
Mikhailov, A., and K. Schlegel, Physical mechanism of strong negative storm effects in the daytime ionospheric F2 region observed with EISCAT, Ann. Geophysicae, 16, 602-608, 1998.

Ogawa, Y., R. Fujii, S. C. Buchert, and S. Nozawa, Simultaneous EISCAT Svalbard and VHF radar observations of ion upflows at different aspect angles, Geophys. Res. Lett., 27, 81-84, 2000.

Pavlov, A. V., The role of vibrationally excited oxygen and nitrogen in the ionosphere during the undisturbed and geomagnetic storm period of 6-12 April, 1990, Ann. Geophysicae, 16, 589601, 1998.

Rees, M. H., and J. C. G. Walker, Ion and electron heating by auroral electric field, Ann. Geophysicae, 24, 193-199, 1968.

Richards, P. G., and D. G. Torr, A factor of 2 reduction in theoretical F2 peak electron density due to enhanced vibrational excitation of $\mathrm{N} 2$ in summer at solar maximum, J. Geophys. Res., 91, 11 331-11 336, 1986.

Shelly, E. G., W. K. Peterson, A. G. Ghielmetti, and J. Geiss, The polar ionosphere as a source of energetic magnetospheric plasma, Geophys. Res. Lett., 9, 941-944, 1982.

Szuszczewicz, E. P., M. Lester, P. Wilkinson, P. Blanchard, M. Abdu, R. Hanbaba, K. Igarashi, S. Pulinets, and B. M. Reddy, A comparative study of global ionospheric responses to intense magnetic storm conditions, J. Geophys. Res., 103, 11665 11 684, 1998.

Torr, M. R., D. G. Torr, M. Zukic, R. B. Johnson, J. Ajello, P. Banks, K. Cole, C. Keffer, G. Parks, B. Tsurutani, and J. Spann, A far ultraviolet imager for the international solar-terrestrial physics mission, Space. Sci. Rev., 71, 329-383, 1995.

Williams, P. J. S., and A. R. Jain, Observations of the high latitude trough using EISCAT, J. Atmos. Terr. Phys., 48, 423434, 1986.

Winser, K. J., G. O. L. Jones, and P. J. S. Williams, Large fieldaligned velocities observed by EISCAT, J. Atmos. Terr. Phys., 50, 379-382, 1988.

Winser, K. J., G. O. L. Jones, and P. J. S. Williams, A quantitative study of the high latitude ionospheric trough using EISCAT's common programs, J. Atmos. Terr. Phys., 48, 893-904, 1986.

Waite, J. H., T. Nagai, J. F. E. Johnson, C. R. Chappell, J. L. Burch, T. L. Killeen, P. B. Hays, G. R. Carignan, W. K. Peterson, and E. G. Shelley, Escape of suprathermal $\mathrm{O}^{+}$ions in the polar cap, J. Geophys. Res., 90, 1619-1630, 1985.

Yau, A. W., E. G. Shelley, W. K. Peterson, and L. Lenchyshyn, Energetic auroral and polar ion outflow at DE 1 altitudes: magnitude, composition, magnetic activity dependence, and long-term variations, J. Geophys. Res., 90, 8417-8432, 1985. 